\title{
The Impact of Agricultural Water Conservation Policy on Economic Growth
}

\author{
Aaron Benson* and Ray Huffaker
}

Texas Tech University, Agricultural and Applied Economics, Box 42132, USA

\begin{abstract}
An agricultural water conservation policy prevalent worldwide encourages producers to improve on-farm irrigation efficiency. Contrary to intention, increasing empirical evidence reveals that this policy may set an irrigation efficiency trap' that worsens water crises by reducing water supplies and jeopardizing economic growth. We derive a pair of testable hydrologic-economic conditions required for the sustained existence of the trap. We do so by modeling an agroindustrial economy patterned after a region (Snake River Plain aquifer, Idaho, USA) that has fallen into the trap. An agricultural sector withdraws water to irrigate crops, and the difference between water withdrawals and the amount consumed by crops (return flow) recharges water supplies used in industrial production. The conditions require that: (1) The rate of return of water in industrial production outweighs the rate of return of water withdrawn to food production; and (2) An inequality relating the elasticities of food production with respect to irrigation withdrawals and irrigation efficiency hold in a particular direction. If empirical testing of these conditions provides evidence of the sustained existence of the irrigation efficiency trap in a given region, policy-makers are well-advised to target more potentially effective agricultural water conservation measures such as reducing irrigated acreage, switching to crops requiring less water, or irrigating current crops at a deficit.
\end{abstract}

Keywords: water policy, irrigation practices, economic growth, droughts.

\section{INTRODUCTION}

Water is vital to sustained economic activity, and even more critically, to life itself. Alarmingly, many parts of the world suffer grave water shortages. The World Resources Institute estimated that 1.7 billion people live in highly stressed river basins [1] where "chronic water shortages threaten food production and hinder economic development" [2].

Technology does not exist to avoid drought by controlling the amount of water that nature provides. Consequently, incoming water earmarked for consumptive economic use is stored and conserved as a hedge against future shortage. Conservation policy focuses on irrigated agriculture as the largest water user worldwide (irrigated agriculture accounts for about $70 \%$ of total water withdrawals [2] and 60 to $80 \%$ of total consumptive water use [3]), and on improved onfarm irrigation technology as a means of growing crops with less water. On-farm irrigation efficiency $(I E)$ is the ratio of consumptive use by crops $(C)$ to water withdrawals $(D)$, i.e., $I E=C / D$. For example, U.S. Secretary of Agriculture Vilsack recently announced that $\$ 42.3$ million of stimulus money from the American Recovery and Reinvestment Act of 2009 would be available for conservation practices including "improving irrigation efficiency" [4]. In addition, U.S. Secretary of the Interior Salazar recently stated: "More and more, we're learning that we can also stretch our water supply by

*Address correspondence to this author at the Texas Tech University, Agricultural and Applied Economics, Box 42132, USA; Tel: 806-742-1921 x 253; E-mail: aaron.benson@ttu.edu being more efficient" [5]. International examples include Australia's 'National Plan for Water Security' which earmarked $\mathrm{A} \$ 10$ billion for agricultural water conservation policies including improved irrigation efficiency [6-8]. The contention that improved irrigation technology conserves water also flourishes in the academic literature. For example, Brabeck-Letmathe [9] advises that society look "for ways to use water in agriculture more efficiently," reasoning that: "Efficient irrigation, for instance, would reduce freshwater withdrawals almost by half" (p. 112). Similarly, Rogers [10] advises that irrigation water can be conserved by "more efficient application of water to farm crops," reasoning that, "even a modest 10 percent rise in irrigation efficiency would free up more water than is evaporated off by all other uses" (p.51).

Increasing empirical evidence demonstrates that this contention fails to hold over broad geographic circumstances. Improved irrigation efficiency can be an effective policy tool to improve salinity control, or to reduce water-logging and leaching of chemicals. However, it also can precipitate 'growth disasters' by increasing water scarcity. We will refer to this as an 'irrigation efficiency trap'. In one case, improved irrigation efficiency failed to stem the rapid decline of groundwater in the North China Plain, which is responsible for a significant amount of China's agricultural production. Improved efficiencies decreased groundwater pumping by $50 \%$ (giving the illusion of conservation), but a later water-balance study by Kendy et al. [11] showed that the groundwater table continued to decline. Long-term food production in China's breadbasket is substantially imperiled [12]. Another recent case is the so-called 'invisible drought' in the commercially vibrant lower portion of the Snake River 
Plain aquifer in Idaho (USA), which has been linked to increased on-farm irrigation efficiency in the upper portion [13]. The Idaho state legislature has spent millions of dollars to purchase water on the open market to prevent the loweraquifer economy from collapsing [14].

To avoid 'throwing oil on the fire', policymakers must better understand the irrigation efficiency trap: Under what circumstances can improved irrigation efficiency be expected to aggravate water-related 'growth disasters'? We formulate an analytical hydrologic-economic growth model to examine this question.

\subsection{Past Work}

To our knowledge, investigating the impact of improved irrigation technology on ongoing economic growth is new to the literature. Past work is confined to case-study hydrological simulations demonstrating the seemingly contradictory result observed in real-world case studies: Improved irrigation efficiency, by reducing water losses at the field level, may eventually increase water stress on a broader geographic scale $[11,15-19]$. The hydrological link uncovered by these studies is that field water losses follow the laws of gravity and conservation of mass to return in liquid form to recharge water systems ('return flows'). So long as water quality is not significantly impaired, return flows, along with natural stream-flows, supplies water to other users. Consequently, reductions in field water losses can translate into substantial reductions in basin-wide water supplies in systems where return flows constitute a significant portion of stream-flow.

Our objective - to derive conceptual linkages between irrigation efficiency and ongoing economic growth-requires that we embed return-flow dynamics (and their dependence on irrigation technology) into an endogenous economic growth model (a branch of economic growth theory pioneered by Romer [20], which identifies activity endogenous to an economy as the engine of economic growth). Past work has embedded a variety of renewable resource specifications into endogenous growth models tailored to investigate particular questions of interest (see, for example, [21, 22] or [23]). Of most direct relevance to our objective are past models integrating a water component into endogenous growth frameworks. Barbier [24] explored the impacts on long-term economic growth of mitigating the impacts of water scarcity with government expenditures on water projects - not with improved irrigation technology. Gaudet et al. [25] investigated water scarcity in a multi-sector economy in which irrigation return flows are modeled exogenously as a fixed fraction of irrigation withdrawals. Alternatively, our objective requires that return flows be modeled endogenously as a function of irrigation efficiency (the policy tool in our investigation).

\subsection{Approach}

We formulate a small closed economy patterned after essential characteristics of the Snake River Plain in Idaho (briefly discussed above). The economy is composed of two sectors that each recycles a capital stock to produce a flow of goods. An agricultural sector withdraws water into irrigated food production. All food is consumed within a single period (that is, within a single year, in this model), and none is im- ported. The full difference between withdrawal and consumptive water use in crop production returns to recharge the water system. An industrial sector employs capital and water remaining from food production (the implicit assumptionconsistent with water use in many parts of the world-is that agricultural has priority rights to water) to produce industrial output. The difference between production and consumption of industrial output (which can effectively be considered as investment) augments the stock of capital. Water is used nonconsumptively in producing industrial output (e.g., hydropower production, microchip processing). Aggregate production in the industrial sector exhibits constant marginal returns to capital (the source of ongoing economic growth), and decreasing marginal returns to water. The agricultural sector does not require capital produced in the industrial sector.

The economic model identifies optimal values of consumption and agricultural water application for a given value of irrigation efficiency. We apply this model economy to derive two conditions necessary to the sustained existence of an irrigation efficiency trap - which occurs when the given value of efficiency increases and the following optimal adjustment in agricultural water application and consumption is unable to achieve the previous level of economic growth; that is, when increasing irrigation efficiency decreases economic growth. One of the required conditions is triggered when the rate of return of water in industrial production outweighs the rate of return of water withdrawn to food production. The economy benefits from increased food production, but suffers an opportunity cost of decreased output in the industrial sector - the source of ongoing economic growth. The second required condition specifies a less intuitive inequality relating the elasticities of food production with respect to irrigation withdrawals and irrigation efficiency.

\section{MATERIALS AND METHODOLOGY}

The conventional formulation of an endogenous economic growth model assumes that there are a large number of $N$ identical infinitely-lived representative agents in a centrally planned economy $[20,26]$. We adapt the formulation to our agro-industrial version by assuming that each farmer withdraws water to irrigate a single food crop, and that a manufacturing sector employs irrigation return flow to produce industrial output.

\subsection{The Water Resource}

The economy is endowed with a renewable public water resource evolving according to:

$$
\frac{d W}{d t}=\delta\left[W_{c}-W(t)\right]-\varepsilon A(t)
$$

where $W(t)$ is the volume of water (in $m^{3}$ ) in year $t$; $W_{c}$ represents the capacity of the river system to store water in various types of impoundments (in $\mathrm{m}^{3}$ ); and $A(t)$ is the volume of water withdrawn by producers for irrigation of a representative crop (in $\mathrm{m}^{3}$ /year). The term $\delta\left[W_{c}-W(t)\right]$ accounts for accumulated water each year, at a rate proportional to remaining storage capacity, where $\delta$ (in units of $1 / t$ ) is fixed at unity so that the term is in flow units. Annual water inflow beyond remaining storage capacity passes through the river system un-stored. The term $\varepsilon A(t)$ measures the volume of water consumptively used by the representative crop each 


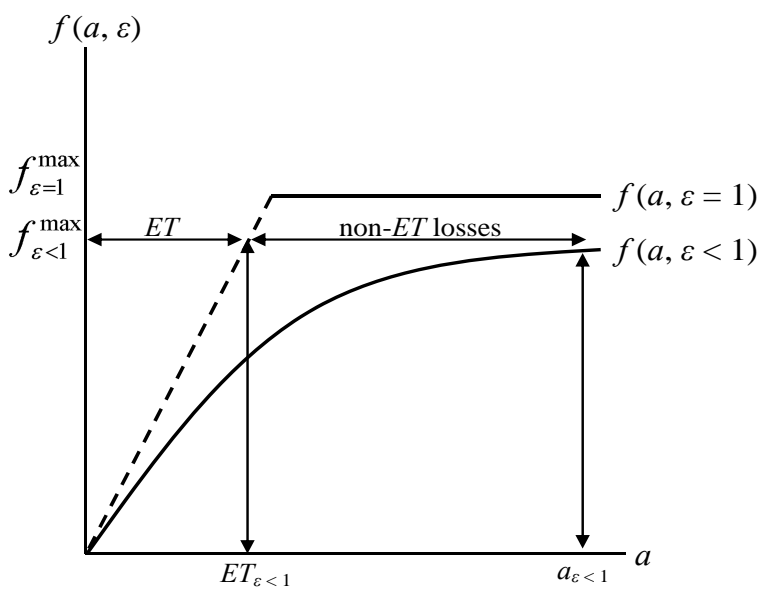

Fig. (1). Irrigation efficiency and crop production.

year where $\varepsilon$ (a unitless parameter) measures on-farm irrigation efficiency. Consistent with the hydrologic regime in many of the world's river systems, water that is not consumed in irrigation is assumed to return to the river via surface/subsurface flows.

\subsection{Agricultural Production}

Crops consume water at a rate determined by the crop size and atmospheric evaporative demand $(E T)$. If a producer's irrigation technology is $100 \%$ efficient $(\varepsilon=1)$, then every unit of withdrawn water satisfies the crop's ET demand. In this case, the agronomic literature indicates that crop yield responds linearly to ET [27]. This is depicted by the dashed curve, $f=f(a, \varepsilon=1)$, in Fig. (1), where the irrigation withdrawal for an individual irrigator is: $a(t)=A(t) / N$. Beyond the 'maximum attainable yield' (determined by exogenous factors such as climate, plant variety, and cultural practices), the crop is incapable of further productivity of water use, and consequently, the yield response is flat (i.e. it is represented by a solid horizontal line).

In practice, a producer's irrigation technology is less than $100 \%$ efficient $(\varepsilon<1)$, and only a fraction of applied water is converted to $E T$ and crop yield. In this case, the crop production function exhibits marginal productivities in applied water that diminish at a rate governed by the farm's irrigation efficiency [27]. As depicted in Fig. (1), the production function, $f=f(a, \varepsilon<1)$, approaches a maximum attainable yield that is below that for a $100 \%$ efficient system. The difference $a_{\varepsilon<1}-E T_{e<1}$ measures applied water not consumed by the crop. Increasing on-farm irrigation efficiency shifts the production function leftward toward the $100 \%$-efficiency curve, increases $E T$, and decreases non-ET losses for a given water application [27].

Consistent with this behavior, we restrict the food production function for a representative producer, $f(a(t), \varepsilon)$, to have positive but declining marginal productivity in applied water: $f^{\prime}(a)>0$ and $f^{\prime \prime}(a)<0$. The function shifts upward when on-farm irrigation efficiency increases, $f^{\prime}(\varepsilon)>0$. Aggregate food production in each period, $F(a(t), \varepsilon)$, is:

$F(t)=N f(a(t), \varepsilon)$

The economy consumes all of the food produced by the irrigated agricultural sector each period so that there is no stored stock
$C_{F}(a(t), \varepsilon)=F(a(t), \varepsilon)$

where $C_{F}(a(t), \varepsilon)$ and $F(a(t), \varepsilon)$ are aggregate food consumption and production rates, respectively.

\subsection{Industrial Production}

The output of a representative agent each period is assumed to follow a Romer-type [28] production function exhibiting constant returns to scale in the individual's own capital stock, $k$, and a flow of services from the agent's share of public water $w$ :

$$
y(k(t), w(t))=\beta_{0} N^{\eta} k(t) w(t)^{1-\alpha} \quad(0<\alpha<1)
$$

where we assume, without loss of generality, that each agent has an equal share of water (which can be thought of as a water right, but one that is fully used each period) so that: $\mathrm{w}(t)=\mathrm{W}(t) / N$. The parameter $\beta$ accounts for technological progress, and depends on the aggregate stock of capital accumulated by $N$ firms, where $\eta$ is a positive exponent reflecting the extent of the knowledge externalities generated among firms [29]. The aggregate production function is an ' $A K$ ' technology; a special characterization of production in which capital has constant marginal productivity in the aggregate and thus is the source of ongoing endogenous growth in the economy [30, footnote 4$]$.

For simplicity, capital is assumed not to depreciate. The evolution of the capital stock per capita is given by:

$\frac{d k}{d t}=y(k(t), w(t))-c_{y}(t)$

where $c_{y}(t)=C_{Y}(t) / N$ is the per capita consumption rate of industrial output.

\subsection{Representative Agent's Problem}

The representative agent in a centralized economy selects, (for an exogenously given irrigation efficiency value, $\varepsilon)$ the per capita consumption rate of industrial output, $c_{y}(t)$, and the per capita withdrawal rate of irrigation water, $a(t)$, which, along with on-farm irrigation efficiency, determines the per capita consumption rate of food, $c_{f}(a, \varepsilon)=C_{f}(a, \varepsilon) / N$. The objective is to maximize social welfare, given by an intertemporal isoelastic utility function (in equation $6 \mathrm{a}$, below), subject to capital appreciation (5), the water resource constraint (1), and a pair of transversality conditions:

$\max _{c_{y}, a} \int_{0}^{\infty} \frac{1}{\gamma}\left(c_{y} c_{f}(a, \varepsilon)^{\varphi}\right)^{\gamma} e^{-\rho t} d t$

subject to

$$
\begin{aligned}
& \frac{d k}{d t}=\dot{k}=y(k, w)-c_{y} \\
& \frac{d w}{d t}=\dot{w}=w_{c}-w-\varepsilon a \\
& \lim _{t \rightarrow \infty} \lambda(t) \geq 0 \quad \text { or } \lim _{t \rightarrow \infty} \lambda(t) k(t)=0 \\
& \lim _{t \rightarrow \infty} \mu(t) \geq 0 \quad \text { or } \lim _{t \rightarrow \infty} \mu(t) w(t)=0
\end{aligned}
$$

Where $w_{c}=W_{c} / N$, and time notation $(t)$ is dropped unless needed for clarity. The parameter $\varphi>0$ measures the 
impact of food consumption on the welfare of the individual, and $\gamma$ determines the intertemporal elasticity of substitution:. $(1-\gamma)^{-1}$. Eliasson and Turnovsky [21], maintain that $\gamma \leq 0$ is strongly supported by the empirical evidence. We impose this restriction in the analysis that follows. The parameter $\rho$ is a real discount rate. The costate variables $\lambda(t)$ and $\mu(t)$ are marginal present values of capital and water, respectively, and are variables introduced to help identify the solution to the constrained maximization problem. The transversality conditions $(6 \mathrm{~d}, \mathrm{e})$ require that the costate variables be nonnegative; and that the value of capital, $\lambda(t) k(t)$, and the value of the public water resource $\mu(t) w(t)$, be driven to zero at the end of the planning period. At that time, all potential profit opportunities must be exhausted. The transversality conditions govern the asymptotic behavior of the solution to Problem (6), and are used to generate the growth limits defining the economy's 'balanced growth path'.

\subsection{Optimality Conditions}

The necessary conditions for optimization are:

$$
\begin{aligned}
& \lambda=c_{y}^{\gamma-1} c_{f}^{\varphi \gamma} \\
& \mu=\frac{\varphi}{\varepsilon} c_{y}^{\gamma} c_{f}^{\varphi \gamma-1} \frac{\partial c_{f}}{\partial a} \\
& \frac{\dot{\lambda}}{\lambda}=\rho-\frac{\partial y}{\partial k} \\
& \frac{\dot{\mu}}{\mu}=1+\rho-\frac{\lambda}{\mu} \frac{\partial y}{\partial w}
\end{aligned}
$$

along with equations of motion $(6 \mathrm{~b}, \mathrm{c})$. The equations in $(7 \mathrm{a}-$ d) are conditions that identify the choice of $c_{y}$ and $a$ that maximizes the net present value of utility of the representative agent (equation 6a). Specifically, condition (7a) requires that the marginal present value of capital, $\lambda$, be equal to the marginal utility of consuming industrial output at the optimal values of $c_{y}$ and $a$. Condition (7b) restricts the marginal present value of water, $\mu$, to equal the marginal utility of withdrawing irrigation water into food production. Condition (7c) is an arbitrage condition equating the rates of return to investing in capital

$\left(\frac{\partial y}{\partial k}\right)$

and consuming capital

$$
\left(\rho-\frac{\dot{\lambda}}{\lambda}\right)
$$

Condition (7d) is an additional arbitrage condition equating the social rates of return in investing water in producing industrial output

$$
\left(\frac{\lambda}{\mu} \frac{\partial y}{\partial w}\right)
$$

to the rate of return of consuming water in food production

$$
\left(1+\rho-\frac{\dot{\mu}}{\mu}\right)
$$

To produce a stationary equilibrium, optimality system (7) is transformed using a new variable: $c=c_{y} / k$ (the ratio of consumption of industrial output to capital). To facilitate identifying the solution of equilibrium levels of the consumption-capital ratio, $c^{e}$, irrigation withdrawal, $a^{e}$, and water, $w^{e}$, the transformed system is re-expressed in matrix form:

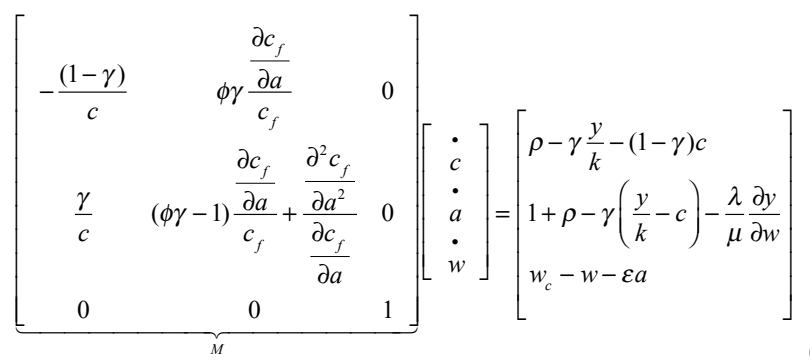

\subsection{The Balanced Growth Path}

In equilibrium, transversality conditions (6d,e) restrict the economy to evolve along a 'balanced growth path' in which variables in the industrial sector-industrial output per capita, $y$, capital held per capita, $k$, and per capita consumption of industrial output, $c_{y}$ - grow at the same asymptotic rate $[26,31]$ :

$\psi^{e}=\frac{\dot{c^{e}}}{c^{e}}=\frac{\dot{a^{e}}}{a^{e}}=\frac{\dot{k}}{k}=\frac{y}{k}\left(w^{e}\right)-c^{e}$

where the last equality results from the constraint (6b). Equilibrium levels of the consumption-capital ratio, $c^{e}$, irrigation withdrawal, $a^{e}$, and water, $w^{e}$, occur when the three equations on the right-hand-side of (8) equal zero. Solving for these levels and substituting them into the balanced (economic) growth rate equation yields the following:

$\psi^{e}=\frac{1}{1-\gamma}\left(\frac{y}{k}\left(w^{e}\right)-\rho\right)$

The balanced growth rate $\psi^{e}$ is measured as the weighted difference between the average product of capital at equilibrium $y / k\left(w^{e}\right)$ and the discount rate $\rho$, where the weight is given by the constant intertemporal elasticity of substitution $(1-\gamma)^{-1}$. Linearized stability analysis of optimality system (8) about equilibrium values $\left(c^{e}, a^{e}, w^{e}\right)$ defines intervals of $c^{e}$ guaranteeing saddle point stability. Saddle point stability justifies focusing on the balanced growth equilibrium by ruling out potential problems of indeterminate equilibria associated with stable dynamics.

Detailed derivations of optimality system (8), the balanced growth path (9) and its stability, and responses of equilibrium values to increased irrigation efficiency (discussed below) are available as an appendix from the lead author.

\subsection{The Irrigation Efficiency Trap}

We now turn to the question posed in the introduction: Under what circumstances would an economy find itself in an 'irrigation efficiency trap' (defined as a situation in which increasing irrigation efficiency increases water scarcity and reduces long-term economic growth)? In particular, we investigate the impact of an exogenous incremental increase in on-farm irrigation efficiency $(\varepsilon)$ on balanced growth levels of 
the industrial-output consumption/capital ratio $\left(c^{e}\right)$, water supply $\left(w^{e}\right)$, irrigation withdrawals $\left(a^{e}\right)$, and balanced growth rate $\left(\psi^{e}\right)$.

We start by describing the response to an increase in irrigation efficiency. As explained above, the right-hand side of equation (8), along with equation (9), represents the optimal values of water supply, irrigation withdrawals and the balanced growth rate. From (8), we can show that the equilibrium quantity of water $\left(w^{e}\right)$ is $w^{e}=w_{c}-\varepsilon a^{e}$. Differentiating that equation with respect to $\varepsilon$ gives

$$
\frac{\partial w^{e}}{\partial \varepsilon}=-a^{e}-\varepsilon \frac{\partial a^{e}}{\partial \varepsilon}
$$

While equation (10) does not completely describe the response of the water supply $\left(w^{e}\right)$ to an increase in efficiency $(\varepsilon)$, it is instructive in understanding how the model adjusts. Specifically, for the effect on the water supply to be nonnegative, the amount of water withdrawn for irrigation must decrease in response to the increase in efficiency (that is, the partial derivative of $a^{e}$ with respect to $\varepsilon$ must be negative). We see that the economy must appropriately decrease irrigation withdrawals or the increase in efficiency will simply increase water consumption at the expense of the industrial sector's output. Similarly, we can differentiate the balanced economic growth rate (equation 9) with respect to $\varepsilon$ to show that increasing irrigation efficiency will decrease growth unless, again, irrigation withdrawals decrease. It can further be shown that, for low levels of irrigation efficiency, these adjustments can be made without sacrificing growth or decreasing the water supply. But, as irrigation efficiency increases, a threshold will be reached above which it is impossible to mitigate the negative growth effects of increasing efficiency by decreasing irrigation withdrawals. Economies that have reached these levels of efficiency are effectively in the irrigation efficiency trap.

To define the conditions in which the trap holds, it is necessary to calculate the implicit derivatives with respect to $\varepsilon$ of the three equations generating the equilibrium values $\left(c^{e}, a^{e}, w^{e}\right)$ and appearing on the right-hand-side of optimality system (8). We solve the resulting matrix system for the response of those variables to an increase in irrigation efficiency (i.e. for $\partial c^{e} / \partial \varepsilon, \partial w^{e} / \partial \varepsilon, \partial a^{e} / \partial \varepsilon$ and $\partial \psi^{e} / \partial \varepsilon$ ), and derive conditions for which $\partial c^{e} / \partial \varepsilon$ and $\partial \psi^{e} / \partial \varepsilon$ are negative.

A pair of conditions jointly guarantee a negative water supply response $\left(\partial w^{e} / \partial \varepsilon<0\right)$. Given maintained restrictions on parameters and functional forms, the same pair of conditions jointly guarantees negative responses in the economy's balanced growth rate $\partial \psi^{\varepsilon} / \partial \varepsilon<0$, and in the industrial-output consumption/capital ratio $\partial c^{e} / \partial \varepsilon<0$. As with those above, derivations of these conditions can be made available to interested readers in the technical appendix.

The first condition in this pair can be shown to require:

$$
\frac{\partial\left(\frac{y}{k}\right)}{\partial w}>\left[\frac{|\gamma| \phi\left(c^{e}\right)^{2}}{\varepsilon N a^{e}}\right] \eta_{c_{f}, a^{e}}
$$

In words, this condition requires the rate of return of water in industrial production (left-hand side) to be proportionately greater than the rate of return of water withdrawn to food production (right-hand side). The latter is measured as the elasticity of food production with respect to irrigation withdrawal $\left(\eta_{c a^{e}}=\partial c_{f} / \partial a \cdot a^{e} / c_{f}\right)$. The irrigation efficiency trap becomes more probable as equilibrium food production has a relatively smaller impact on social welfare (small $\phi)$ and consumptive water use in irrigation exerts greater pressure on the water supply (large $\varepsilon a^{e}$ ) because the bracketed term weighing the elasticity on the right hand side of (11) decreases in magnitude.

The second condition in the pair can be written as:

$$
c^{e}\left[\frac{\partial c_{f}}{\partial a} \frac{\partial c_{f}}{\partial \varepsilon}-c_{f} \frac{\partial\left(\frac{\partial c_{f}}{\partial a}\right)}{\partial \varepsilon}\right]<-\frac{a^{e}}{\varepsilon N} c^{e}\left[c_{f} \frac{\partial^{2} c_{f}}{\partial a^{2}}-\left(\frac{\partial c_{f}}{\partial a}\right)^{2}\right]
$$

or, in terms of elasticities:

$\eta_{c_{f}, \varepsilon}-\eta_{\frac{\partial c_{f}}{\partial a}, \varepsilon}<\eta_{c_{f}, a^{e}}-\eta_{\frac{\partial c_{f}}{\partial a}, a^{e}}$

where ${ }^{\eta_{c_{f}, \varepsilon}}$ is the elasticity of food production with respect to on-farm irrigation efficiency, $\frac{\eta_{\partial c_{f}}, \varepsilon}{\partial a}$ is the elasticity of the marginal product of irrigation water in food production with respect to on-farm irrigation efficiency, and $\frac{\eta_{\partial c_{f}}, a^{e}}{\partial a}$ is the elasticity of the marginal product of irrigation water in food production with respect to irrigation withdrawal. This condition holds when the net of the elasticities of food production and its marginal product with respect to withdrawn water outweighs the net of the elasticities of food production and its marginal product with respect to on-farm irrigation efficiency.

In sum, paired conditions (11) and (12b) provide testable necessary conditions for the sustained existence of the irrigation efficiency trap in an agro-industrial economy. If these conditions are found to hold, this provides evidence that an agricultural water conservation policy increasing onfarm irrigation efficiency may unintentionally worsen a water crisis by increasing consumptive water use in the agricultural sector, reducing irrigation return flow supplying water to the industrial sector, and shrinking sustained regional economic growth. The irrigation efficiency trap can be described as the situation in which all possible economic gains from increasing irrigation efficiency have already been exhausted, and any further increases in irrigation efficiency will push the economy away from its optimal outcome.

\section{DISCUSSION AND CONCLUSION}

Our paper is motivated by an agricultural water conservation policy that, contrary to expectation and intention, has worsened water crises worldwide by contributing to the continued reduction of scarce water supplies and jeopardizing ongoing economic growth. The policy-encouraging agricultural producers to increase on-farm irrigation efficiencycan counterproductively increase consumptive water use in agriculture, and reduce ongoing economic growth by decreasing irrigation return flows that replenish water supplies for other productive sectors in the economy. This can appar- 
ently occur even when withdrawals are "optimally" decreased in response to the increase in efficiency. We refer to this as an 'irrigation efficiency trap.'

We investigate the potential for an irrigation efficiency trap in a small closed economy patterned after essential characteristics of the Snake River Plain in Idaho (USA). The region experiences a so-called 'invisible drought' due to historical increases in on-farm irrigation efficiency in the upper portion of the aquifer that have reduced water supplies relied upon by an industrial sector in the lower portion. In our model, an agricultural sector withdraws water into irrigated food production; the difference between water withdrawals and the amount consumptively used in crop production returns to recharge water supplies available for industrial production; and aggregate production in the industrial sector exhibits constant marginal returns to capital-the source of ongoing economic growth.

We find that conditions required for the sustained existence of the irrigation efficiency trap are: (1) The rate of return of water in industrial production outweigh the rate of return of water withdrawn to food production; and (2) an inequality relating the elasticities of food production with respect to irrigation withdrawals and irrigation efficiency hold in a particular direction. If empirical testing of these conditions provides evidence of the sustained existence of the irrigation efficiency trap in a given region, policy makers are well-advised to target more potentially effective agricultural water conservation measures such as reducing irrigated acreage, switching to crops requiring less water, or irrigating current crops at a deficit. And, while not a policy that could achieve short-term benefits, increasing resources devoted to developing and adopting drought-tolerant crops would effectively decrease the chance that a region finds itself in the irrigation efficiency trap in the long-run.

\section{CONFLICT OF INTEREST}

The authors confirm that this article content has no conflicts of interest.

\section{ACKNOWLEDGEMENT}

Declared none.

\section{REFERENCES}

[1] Revenga C, Brunner J, Henninger N, Payne R, Kassem K. Pilot analysis of global ecosystems: freshwater systems. World Watch Paper 128, Worldwatch Institute, Washington, DC 2000.

[2] Johnson N, Revenga C, Echeverria J. Manag water for people and nature. Science 2001; 292: 1071-2.

[3] Tiwari D, Dinar A. Role and use of economic incentives in irrigated agriculture. Working Paper. World Bank, Washington, DC 2000.

[4] United States Department of Agriculture. News Release No. 0190.09, Office of Communications, Washington, DC 2009

[5] Hagengruber M. Salazar calls for efficiency in water use. Billings Gazette; 10 August 2009.
[6] Ancev T, Vervoort W. The national plan for water security: Taking over the role of a market? 2007. Available from http://www.agrifood.info/connections/2007/Ancer_Vervoort.html.

[7] Friedman T. The Aussie 'Big Dry.' New York Times; 4 May 2007.

[8] The Economist. Australia's water shortage: The big dry. 26 April 2007.

[9] Brabeck-Letmathe P. A water warning. The Economist; 19 November 2008.

[10] Rogers P. Facing the freshwater crisis. Sci Am 2008; 299:46-53.

[11] Kendy E, Molden D, Steenhuis T, Liu C. Policies drain the North China Plain: agricultural policy and groundwater depletion in Luancheng County, 1949-2000. IWMI Res Rep 2003; 71. IWMI Colombo, Sri Lanka.

[12] Brown L. Chinese Water Table Torture. Grist 2001: Available from: http://www.grist.org/news/maindish/2001/10/26/table/

[13] Johnson G, Sullivan W, Cosgrove D, Schmidt R. Recharge of the Snake River Plain Aquifer: transitioning from incidental to managed. J Am Water Resour Associ 1999; 35: 123-31.

[14] Schlender Report. U.S. farmers in west grow more with less water. Voice of Am News; 19 March 2007.

[15] Allen R, Willardson L, Fredriksen H. Water use definitions and their use for assessing the impacts of water conservation. Proceedings of the ICID Workshop: Sustainable Irrigation in Areas of Water Scarcity and Drought, deJager J, Vermes L, Ragab R, Eds., 1112 September 1997, Oxford, England.

[16] Cai X, Rosegrant MW, Ringler C. Physical and economic efficiency of water use in the river basin: implications for efficient water management. Water Resour Res 2003; 39: 1013, doi:10.1029/2001WR000748.

[17] Clemmens A, Allen R. Impact of agricultural water conservation on water availability. ASCE EWRI World Water and Environmental Resources Conference, 15-19 May 2005; Anchorage, AK, USA.

[18] Soloman K, Davidoff B. On the relationship between unit and subunit irrigation performance. Trans ASEA 1999; 42: 115-22.

[19] Ward F, Pulido-Velazques M. Water conservation in irrigation can increase water use. Proc Natl Acad Sci 2008; 105: 18215-20.

[20] Romer P. Endogenous technological change. J Pol Econ 1990; 98: S71-S102.

[21] Eliasson L. Turnovsky S. Renewable resources in an endogenously growing economy: balanced growth and transitional dynamics. J Environ Econ Manag 2004; 48: 1018-49.

[22] McAusland C. Learning by doing in the presence of an open access renewable resource: Is Growth Sustainable? Natural Res Mod 2005; 18: 41-68.

[23] Lopez R, Anriquez G, Gulati S. Structural change and sustainable development. J Environ Econ Manag 2007; 53: 307-22.

[24] Barbier E. Water and economic growth. Econ Rec 2004; 80: 1-16.

[25] Gaudet G, Moreaux M, Withagen C. The Alberta dilemma: Optimal sharing of a water resource by an agricultural and an oil sector. J Environ Econ Manag 2006; 52: 548-66.

[26] Schmidt G. Dynamics of Endogenous Economic Growth: A Case Study of the "Romer Model". Elsevier: Amsterdam 2003.

[27] Klotke N, Hubbard K, Kranz W, Watts D. Evapotranspiration (ET) or Crop Water Use. NebGuide G90-992, Cooperative Extension, Institute of Agriculture and Natural Resources, University of Nebraska-Lincoln; 1990.

[28] Romer P. Increasing returns and long-term growth. J Pol Econo 1986; 94: 1002-37.

[29] Frankel M. The production function in allocation and growth: a synthesis. Am Econ Rev 1962; 52: 995-1022.

[30] Turnovsky S. Fiscal policy, elastic labor supply, and endogenous growth. J Monet Econ 2000; 45: 185-210.

[31] Romer D. Advanced Macroeconomics, $3^{\text {rd }}$ ed., New York: McGraw-Hill Irwin 2006.

\begin{tabular}{ll}
\hline Received: August 13, 2012 & Revised: October 23, 2012
\end{tabular}

Accepted: October 26, 2012

(C) Benson and Huffaker; Licensee Bentham Open.

This is an open access article licensed under the terms of the Creative Commons Attribution Non-Commercial License (http://creativecommons.org/licenses/by-nc/3.0/) which permits unrestricted, non-commercial use, distribution and reproduction in any medium, provided the work is properly cited. 